\title{
Accuracy and reproducibility of aortic annulus sizing using a dedicated three-dimensional computed tomography reconstruction tool in patients evaluated for transcatheter aortic valve replacement
}

\author{
Stefan Stortecky1, MD; Dik Heg², PhD; Steffen Gloekler'1, MD; Peter Wenaweser ${ }^{1}, \mathrm{MD}$; \\ Stephan Windecker ${ }^{2}$, MD; Lutz Buellesfeld ${ }^{1 *}$, MD \\ 1. Department of Cardiology, Swiss Cardiovascular Centre, Bern University Hospital, Bern, Switzerland; 2. Department of \\ Clinical Research, Clinical Trials Unit, Bern, Switzerland
}

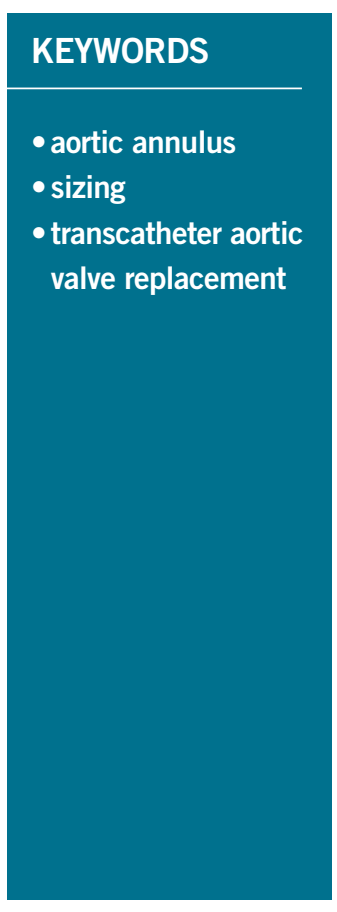

\begin{abstract}
Aims: To evaluate the accuracy and reproducibility of aortic annulus sizing using a multislice computed tomography (MSCT) based aortic root reconstruction tool compared with conventional imaging among patients evaluated for transcatheter aortic valve replacement (TAVR).

Methods and results: Patients referred for TAVR underwent standard preprocedural assessment of aortic annulus parameters using MSCT, angiography and transoesophageal echocardiography (TEE). Threedimensional (3D) reconstruction of MSCT images of the aortic root was performed using 3 mensio ( 3 mensio Medical Imaging BV, Bilthoven, The Netherlands), allowing for semi-automated delineation of the annular plane and assessment of annulus perimeter, area, maximum, minimum and virtual diameters derived from area and perimeter (aVD and pVD). A total of 177 patients were enrolled. We observed a good inter-observer variability of 3D reconstruction assessments with concordance coefficients for agreement of 0.91 (95\% CI: $0.87-0.93)$ and $0.91(0.88-0.94)$ for annulus perimeter and area assessments, respectively. 3D derived pVD and aVD correlated very closely with a concordance coefficient of 0.97 (0.96-0.98) with a mean difference of $0.5 \pm 0.3 \mathrm{~mm}$ (pVD-aVD). 3D derived pVD showed the best, but moderate concordance with diameters obtained from coronal MSCT $(0.67,0.56-0.75 ; 0.3 \pm 1.8 \mathrm{~mm})$, and the lowest concordance with diameters obtained from TEE $(0.42,0.31-0.52 ; 1.9 \pm 1.9 \mathrm{~mm})$.
\end{abstract}

Conclusions: MSCT-based 3D reconstruction of the aortic annulus using the 3 mensio software enables accurate and reproducible assessment of aortic annulus dimensions.

\footnotetext{
*Corresponding author: Department of Cardiology, Swiss Cardiovascular Center Bern, Bern University Hospital, 3010 Bern, Switzerland.E-mail: lutz.buellesfeld@insel.ch
} 


\section{Introduction}

Transcatheter aortic valve replacement (TAVR) has rapidly evolved into an effective treatment for high-risk patients with symptomatic aortic valve stenosis. In view of the available therapeutic modalities, appropriate treatment allocation as well as device selection deserve careful consideration by a multidisciplinary team of cardiac surgeons, interventional cardiologists and cardiac imaging specialists ${ }^{1}$. In addition, meticulous assessment of the aortic root anatomy is a prerequisite to accurate determination of the dimensions of this structure $e^{2,3}$ in order to avoid annulus-prosthesis mismatch, which may result in preventable complications including annulus rupture, device embolisation or significant paravalvular regurgitation ${ }^{4}$. In contrast to surgical aortic valve replacement with direct $i n$ situ assessment of aortic annulus anatomy, TAVR relies on preprocedural evaluation using noninvasive imaging modalities. Several imaging techniques including transthoracic (TTE) and transoesophageal echocardiography (TEE), contrast-enhanced multislice computed tomography (MSCT), magnetic resonance imaging (MRI) and invasive angiography are used in clinical practice ${ }^{5-8}$. While conventional TTE, TEE and angiography create two-dimensional images, MSCT, MRI and recently introduced three-dimensional TEE techniques are capable of threedimensional spatial reconstructions ${ }^{9}$. Given the complex anatomy of the aortic root with an ovally shaped aortic annulus and left ventricular outflow tract ${ }^{2,6,9,10}$ and dynamic changes during the heart cycle ${ }^{11,12}$, previous reports on annulus imaging comparing conventional twodimensional techniques revealed significant discrepancies ${ }^{13,14}$. A dedicated MSCT reconstruction tool has recently been introduced, which allows for a three-dimensional assessment of the aortic root (3mensio Medical Imaging BV, Bilthoven, The Netherlands) ${ }^{3,15,16}$. However, inter-observer variability and accuracy of this method compared to standard imaging techniques have not yet been evaluated. In addition, three-dimensional annulus imaging allows for assessment of annulus area and perimeter and related virtual diameters, but there is currently no accepted gold standard regarding the best parameter for device selection among the various parameters obtainable. The objective of this single-centre study was to evaluate the accuracy and reproducibility of aortic annulus sizing using 3 mensio in comparison to conventional standard imaging techniques in patients planned to undergo TAVR. A secondary objective of this study was to evaluate the interdependence of virtual diameters derived from area and perimeter assessments in clinical practice.

\section{Editorial, see page 294}

\section{Methods \\ PATIENT POPULATION}

TAVR candidates who underwent contrast-enhanced MSCT for preprocedural aortic root assessment at our institution between October 2007 and March 2012 were enrolled. The study population comprised a retrospective (TAVR procedure between October 2007 and August 2011) and a prospective patient cohort (TAVR procedure between September 2011 and March 2012). The retrospective group underwent pre-interventional imaging including left and right heart catheterisation, TEE and MSCT and was used for the inter-modality assessments.
Both retrospective and prospective cohorts were pooled for the interobserver analysis as well as for the intra-modality comparisons of parameters derived from 3mensio three-dimensional MSCT reconstructions. All patients were considered to be at increased risk for surgical aortic valve replacement or inoperable due to the pre-existing clinical conditions, medical history and comorbidities as judged by the institutional Heart Team, consisting of interventional cardiologists and cardiovascular surgeons. Final treatment allocation was based on clinical as well as anatomical characteristics. All patients provided written, informed consent for data collection and analysis.

\section{IMAGING ASSESSMENT}

\section{MSCT IMAGING}

MSCT assessment of the aortic root was performed on either a Siemens Somatom Sensation Cardiac 64 scanner with a slice collimation of $1.5 \mathrm{~mm}$, or a Siemens Somatom Definition Flash DualSource scanner with a slice collimation of $0.6 \mathrm{~mm}$, tube voltage of 100 or $120 \mathrm{kV}$ and tube current according to patient size (Siemens Medical Solutions, Inc., Forchheim, Germany). Each patient received an intravenous injection of 80 to $120 \mathrm{ml}$ of contrast medium via the antecubital vein at a flow rate of $5 \mathrm{ml} / \mathrm{s}$. Automated peak enhancement detection in the descending aorta at the level of the diaphragm with a threshold of $100 \mathrm{HU}$ was used for timing of the scan. Data acquisition was performed during a mid-inspiratory breath-hold in a craniocaudal direction, while the ECG was recorded simultaneously to allow triggering and retrospective gating. Images were reconstructed in the diastolic phase at $60 \%$ of the RR interval.

Standard axial and sagittal views were used for initial anatomical orientation followed by coronal and a single oblique sagittal view reconstruction through the aortic valve plane. Both coronal (MSCTcor) and sagittal oblique views (MSCTsag) were used for the assessment of aortic annulus dimensions, as described elsewhere ${ }^{8}$ (Figure 1).

The same standard axial images were used for a three-dimensional aortic root reconstruction by 3 mensio, an MSCT-based software tool whose technical details have been described elsewhere ${ }^{15,16}$. Briefly, following segmentation of the aortic root, the annular plane was manually identified as the plane connecting the nadirs of the three aortic cusps. Each of the following parameters was obtained in the annular plane: minimum and maximum lumen diameter, area and perimeter by manual polygonal border tracing (Figure 2). Virtual aortic annulus diameters (VD) were calculated from the annular perimeter $(\mathrm{pVD}=$ perimeter/pi) and annular area $(\mathrm{aVD}=\sqrt{ }[4 *$ area/pi $])$.

\section{TRANSOESOPHAGEAL ECHOCARDIOGRAPHY}

In TEE examinations, annulus dimensions were assessed using the $110^{\circ}$ to $140^{\circ}$ long-axis view (3-chamber view) measuring the distance between the nadirs of the right and the non-coronary aortic cusps during diastole in the zoom mode (Figure 1).

\section{ANGIOGRAPHY}

Aortic root angiography was performed with an indexed pigtail catheter and standardised injections of $25-30 \mathrm{ml}$ contrast at a rate of $15 \mathrm{ml} / \mathrm{s}$ in a projection ( $\mathrm{LAO} 0^{\circ}-20^{\circ}$ ) with alignment of all three aortic cusps in a single plane. The aortic annulus was measured from the hinge point of the left coronary to the non-coronary cusp (Figure 1). 

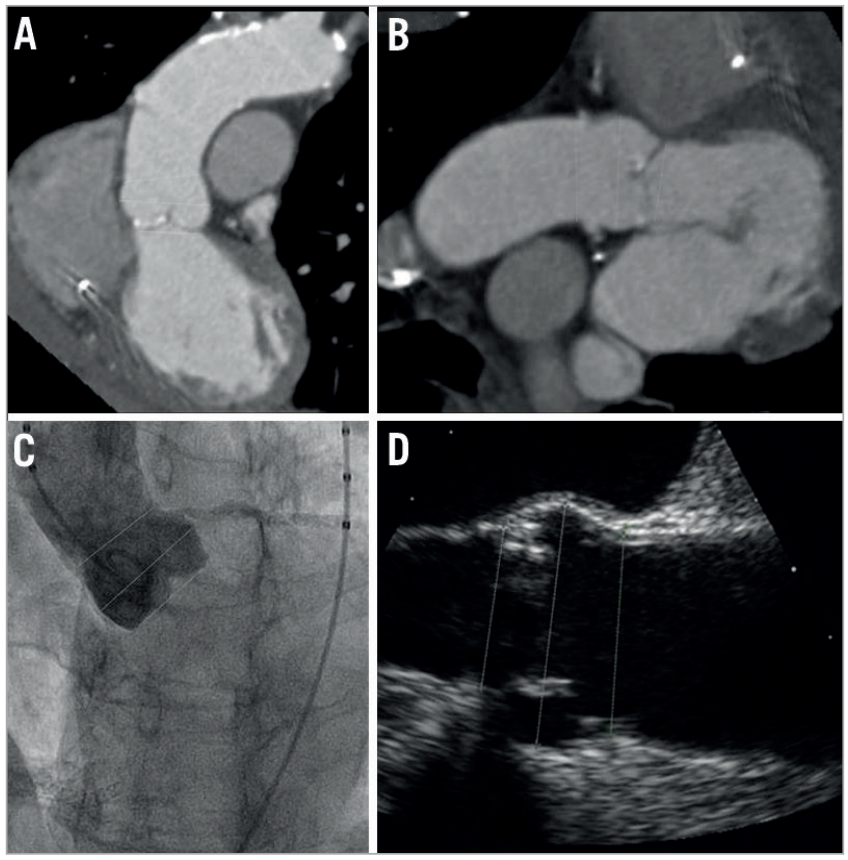

Figure 1. Standard aortic root assessment during the preoperative evaluation for TAVR using multislice computed tomography.

A) Coronal reconstruction. B) Sagittal reconstruction. C) Aortic root angiography with an indexed pigtail catheter. D) Transoesophageal echocardiography.
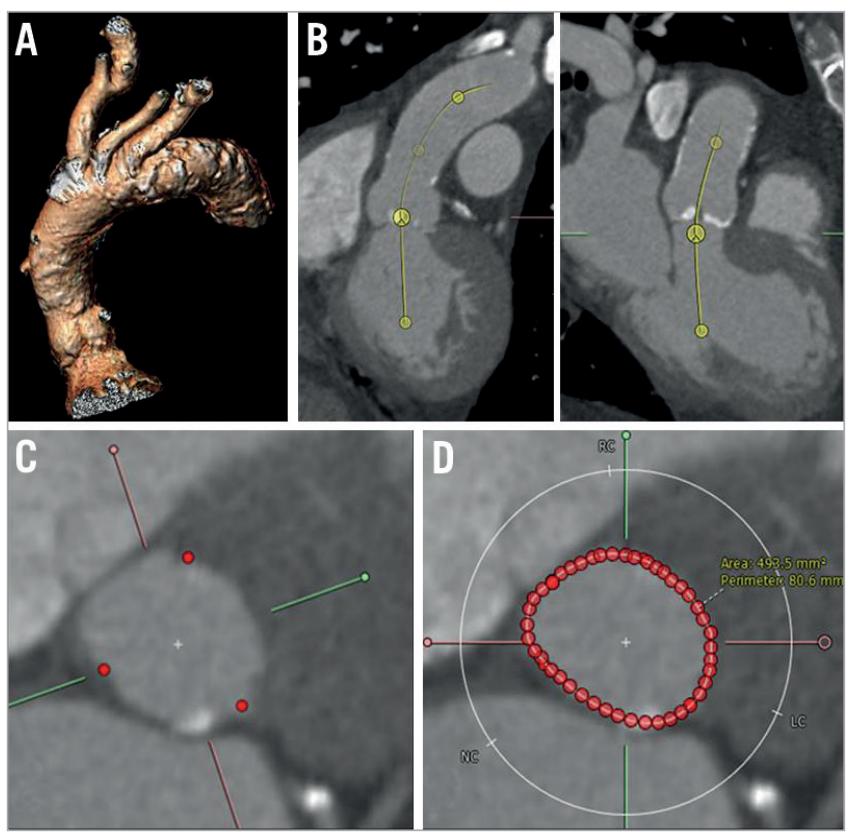

Figure 2. Imaging assessment using the 3mensio post-processing software. A) $3 D$ reconstruction of the aortic root. B) Evaluation of the annulus level in double oblique coronal and sagittal views. C) In the short-axis view, the annulus level is set at the nadir of the three aortic cusps. D) Manual tracing of the aortic annulus borders; automated calculation of the aortic annulus perimeter and the aortic annulus area.

\section{IMAGING ANALYSIS}

MSCT aortic annulus measurements were independently performed by two experienced observers (SS and LB) who were blinded to clinical, echocardiographic as well as baseline clinical data. Measurements in the echocardiographic and angiographic planes were performed by a specially trained operator (SG) who was blinded to clinical, MSCT and procedural data. Aortic annulus dimensions using standard imaging techniques were compared to pVD and aVD obtained from 3 mensio.

\section{Statistical analysis}

Patient demographics were prospectively collected and entered in a dedicated database held at CTU Bern, Switzerland. All statistical analyses were performed by a statistician of an academic clinical trials unit (DH). Continuous measures are presented as means and standard deviation (SD), while categorical variables are presented as frequency and percentages. Concordance in the measurement of the aortic annulus diameter was compared paired for the four standard imaging methods (angiography, TEE, MSCTcor, MSCTsag) (inter-modality concordance), using Lin's concordance correlation coefficients ${ }^{17}$. All patients in the retrospective cohort were independently measured by two experienced observers (SS and LB) to assess the inter-rate concordance of the novel automated imaging technique using the 3 mensio post-processing software. Concordance between the two observers was shown using correlation figures and Bland-Altman plots, where the $\mathrm{x}$-axis represents the mean diameter assessed by the two observers and the $y$-axis shows the difference in assessment of the two observers. The line of perfect agreement at difference is 0 , the limits of agreement and the number of cases (\%) being outside this agreement. All statistical tests were two-sided, and all analyses were performed using Stata 12 (StataCorp LP, College Station, TX, USA).

\section{Results STUDY COHORT}

A total of 177 patients were included in this study, 127 of whom belonged to the retrospective cohort and 50 to the prospective cohort. Baseline clinical characteristics are summarised in Table 1. The mean patient age was $82.5 \pm 5.5$ years and $55 \%$ were female. All patients had degenerative symptomatic severe aortic stenosis (64\% of patients with NYHA Class III/IV) with an aortic valve area of $0.6 \pm 0.2 \mathrm{~cm}^{2}$ and a mean transvalvular aortic gradient of $42.8 \pm 17.3 \mathrm{mmHg}$. Left ventricular ejection fraction was $51.6 \pm 15.5 \%$, and $30 \%$ of patients presented with atrial fibrillation. All patients were deemed at increased surgical risk as indicated by a mean logistic EuroSCORE of $23.4 \pm 13.3 \%$ and STS risk score of $6.2 \pm 4.0 \%$.

\section{MENSIO IMAGING ASSESSMENT}

Intra-class correlation coefficients (ICC) between the two assessors showed a good agreement for all annulus measurements using the three-dimensional reconstruction software (Figure 3). Similarly, concordance correlation was excellent for measurements of the annulus perimeter $(0.91,95 \% \mathrm{CI}$ : $0.87-0.93)$ and area $(0.91,95 \%$ 


\begin{tabular}{|lccccc|}
\hline & Difference & LOA & \multicolumn{2}{c}{ ICC } & CCC \\
& & & Single rater & Average rater & \\
\hline Diameter aortic annulus max. $(\mathrm{mm})$ & $-0.23 \pm 1.45$ & -3.08 to 2.62 & $0.85(0.80-0.89)$ & $0.92(0.89-0.94)$ & $0.85(0.80-0.89)$ \\
Diameter aortic annulus min. $(\mathrm{mm})$ & $-0.20 \pm 1.46$ & -3.06 to 2.67 & $0.78(0.70-0.84)$ & $0.88(0.82-0.91)$ & $0.78(0.70-0.84)$ \\
Perimeter aortic annulus $(\mathrm{mm})$ & $0.59 \pm 3.06$ & -5.40 to 6.59 & $0.91(0.87-0.93)$ & $0.95(0.93-0.97)$ & $0.91(0.87-0.93)$ \\
Area aortic annulus $\left(\mathrm{mm} \mathbf{m}^{2}\right)$ & $5.69 \pm 33.30$ & -59.58 to 70.96 & $0.91(0.88-0.94)$ & $0.95(0.94-0.97)$ & $0.91(0.88-0.94)$ \\
Virtual diameter - aortic annulus (perimeter derived $-\mathrm{mm})$ & $0.19 \pm 0.97$ & -1.72 to 2.10 & $0.91(0.87-0.93)$ & $0.95(0.93-0.97)$ & $0.91(0.87-0.93)$ \\
Virtual diameter - aortic annulus (area derived $-\mathrm{mm})$ & $0.16 \pm 0.92$ & -1.65 to 1.97 & $0.91(0.87-0.94)$ & $0.95(0.93-0.97)$ & $0.91(0.87-0.94)$ \\
\hline
\end{tabular}

Difference: mean difference between the two observers; LOA: Bland \& Altman's limit-of-agreement of the two observers; ICC: intra-class correlation coefficient; CCC: concordance correlation coefficient for agreement
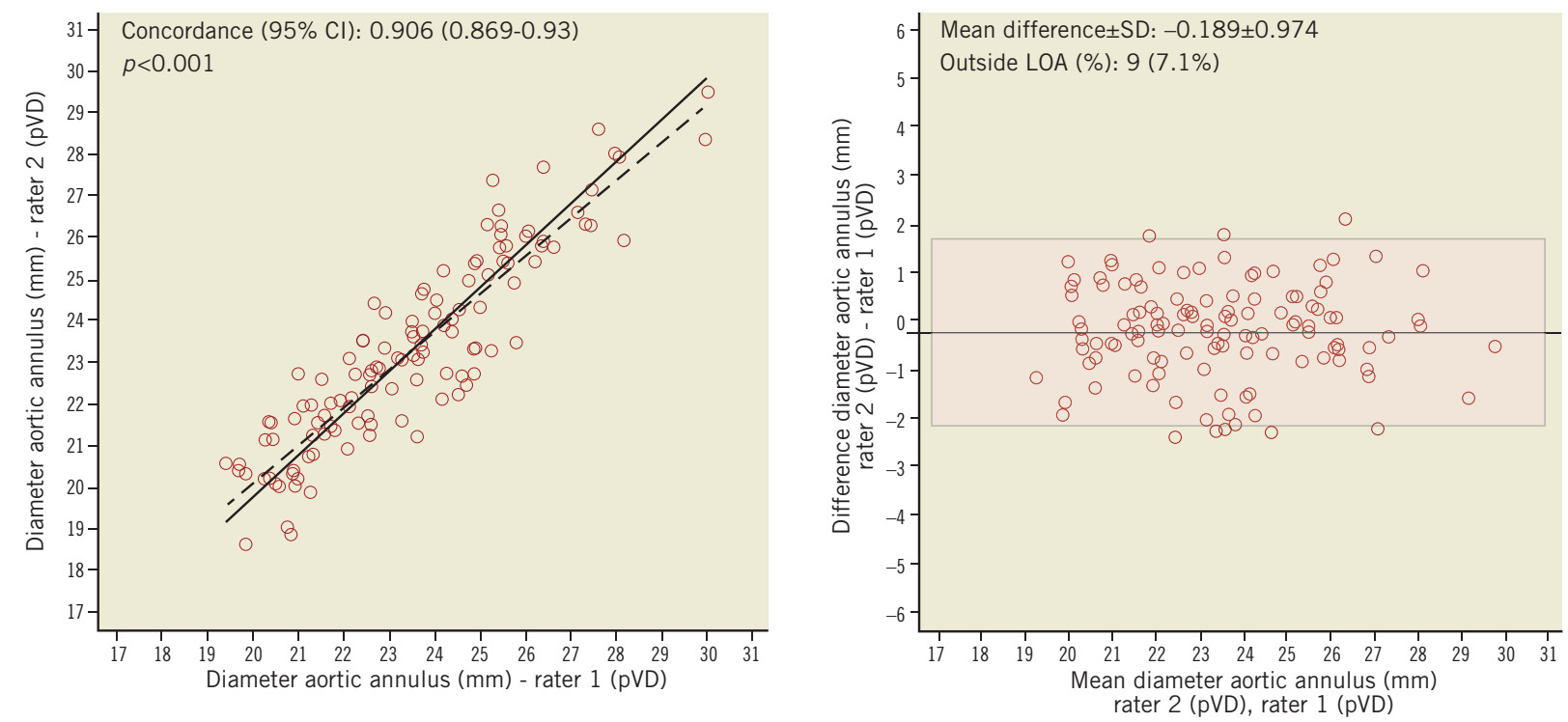

Figure 3. Inter-observer variability using intra-class coefficients (ICC) and concordance correlation coefficient (CCC). Correlation figure and Bland-Altman analysis for the inter-observer variability of the perimeter-derived virtual aortic diameter $(p V D)$.

CI: $0.88-0.94)$, and good for the assessment of minimal $(0.78,95 \%$

CI: $0.70-0.84)$ and maximal aortic annulus diameters $(0.85,95 \%$

CI: $0.80-0.89)$.

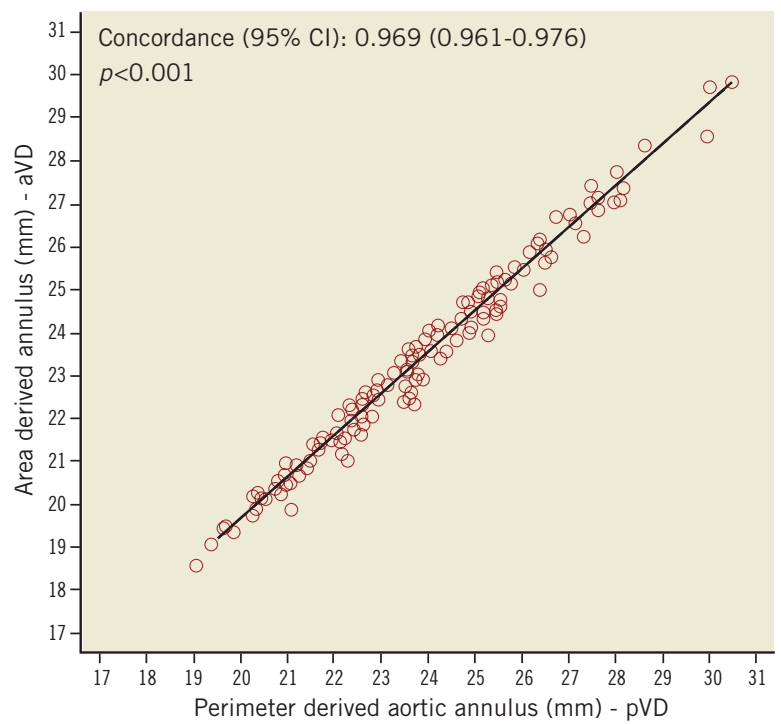

Assessments of $\mathrm{pVD}$ and aVD showed an excellent correlation with slightly smaller dimensions for the aVD (mean difference $-0.5 \pm 0.3 \mathrm{~mm}$; concordance 0.97, 95\% CI: 0.96-0.98) (Figure 4).

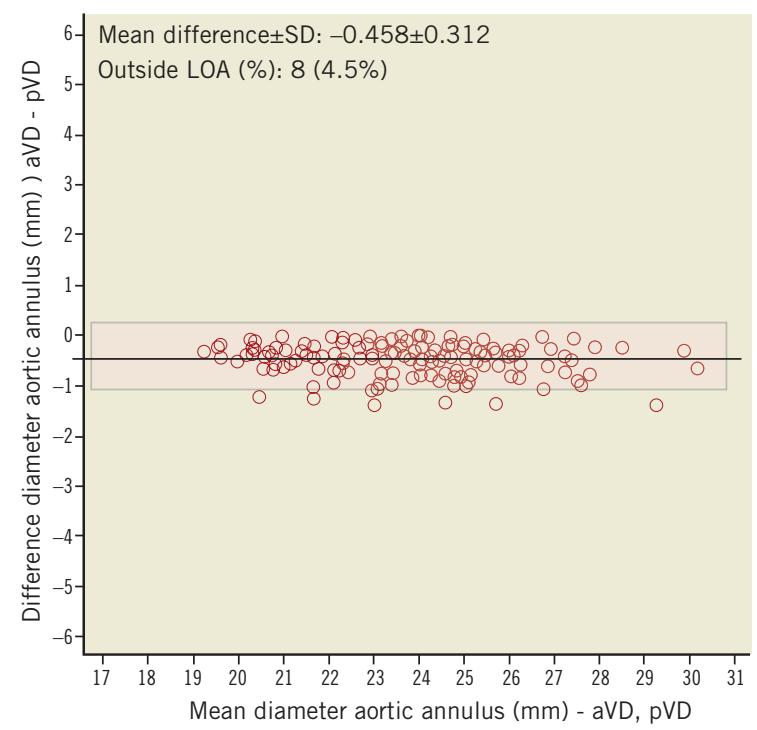

Figure 4. Imaging assessment using 3mensio-derived virtual diameters: differences between area (aVD) and perimeter ( $p V D)$ derived aortic annulus diameters. 
Table 1. Baseline clinical characteristics.

\begin{tabular}{|c|c|c|}
\hline \multicolumn{2}{|l|}{ 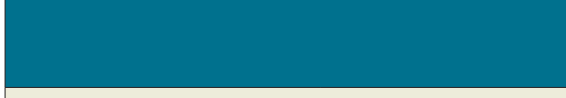 } & $\begin{array}{l}\text { Study population } \\
\qquad(\mathrm{n}=177)\end{array}$ \\
\hline \multicolumn{2}{|l|}{ Age (years) } & $82.5 \pm 5.5$ \\
\hline \multicolumn{2}{|l|}{ Female gender, $\mathrm{n}(\%)$} & $97(55 \%)$ \\
\hline \multicolumn{2}{|l|}{ Body mass index (kg/m²) } & $25.6 \pm 4.5$ \\
\hline \multicolumn{3}{|l|}{ Cardiac risk factors } \\
\hline \multicolumn{2}{|l|}{ Diabetes mellitus, $n(\%)$} & $49(28 \%)$ \\
\hline \multicolumn{2}{|c|}{ Hypercholesterolaemia, n (\%) } & $107(60 \%)$ \\
\hline \multicolumn{2}{|l|}{ Hypertension, $n(\%)$} & $134(76 \%)$ \\
\hline \multicolumn{2}{|l|}{ Current smoker, $n(\%)$} & $22(12 \%)$ \\
\hline \multicolumn{3}{|l|}{ Past medical history } \\
\hline \multicolumn{2}{|c|}{ Previous myocardial infarction, $\mathrm{n}(\%)$} & $27(15 \%)$ \\
\hline \multicolumn{2}{|c|}{ Previous coronary artery bypass graft, $n(\%)$} & $31(18 \%)$ \\
\hline \multicolumn{2}{|c|}{ Previous percutaneous coronary intervention, $n$ (\%) } & $47(27 \%)$ \\
\hline \multicolumn{2}{|l|}{ Previous stroke, n (\%) } & $15(8 \%)$ \\
\hline \multicolumn{2}{|c|}{ Peripheral vascular disease, $\mathrm{n}(\%)$} & $30(17 \%)$ \\
\hline \multicolumn{2}{|c|}{ Chronic obstructive pulmonary disease, $n(\%)$} & $28(16 \%)$ \\
\hline \multicolumn{2}{|l|}{ Atrial fibrillation, $n(\%)$} & $52(30 \%)$ \\
\hline \multicolumn{2}{|c|}{ Coronary artery disease, $n(\%)$} & $110(62 \%)$ \\
\hline \multicolumn{2}{|c|}{ Pulmonary artery hypertension (PAPs $>60 \mathrm{mmHg}$ ) } & $53(30 \%)$ \\
\hline \multicolumn{2}{|l|}{ Aortic valve area $\left(\mathrm{cm}^{2}\right)$} & $0.6 \pm 0.2$ \\
\hline \multicolumn{2}{|c|}{ Mean transaortic gradient (mmHg) } & $42.8 \pm 17.3$ \\
\hline \multicolumn{2}{|c|}{ Left ventricular ejection fraction (\%) } & $51.6 \pm 15.5$ \\
\hline \multicolumn{2}{|c|}{ Renal failure (eGFR <60 ml/min/1.73m²) } & $119(67 \%)$ \\
\hline \multicolumn{3}{|l|}{ Symptoms } \\
\hline \multirow{2}{*}{$\begin{array}{l}\text { New York Heart Association } \\
\text { (NYHA) Functional Class }\end{array}$} & NYHA I + II, n (\%) & $63(36 \%)$ \\
\hline & NYHA III + IV, n (\%) & $114(64 \%)$ \\
\hline \multicolumn{3}{|l|}{ Risk assessment } \\
\hline \multicolumn{2}{|l|}{ Logistic EuroSCORE (\%) } & $23.4 \pm 13.3$ \\
\hline \multicolumn{2}{|l|}{ STS score (\%) } & $6.2 \pm 4.0$ \\
\hline
\end{tabular}

Figure $\mathbf{5}$ shows the mean diameter of the aortic annulus obtained from the various imaging modalities. Comparing $\mathrm{pVD}$ to diameters calculated by standard imaging techniques, the highest concordance level was observed between MSCTcor and pVD (mean difference $-0.3 \pm 1.8 \mathrm{~mm}$; concordance $0.67,95 \% \mathrm{CI}$ : $0.56-0.76$ ), while the lowest agreement was found between TEE and pVD (mean difference $-1.9 \pm 1.9 \mathrm{~mm}$; concordance $0.42,95 \% \mathrm{CI}: 0.31-0.52$ ) (Figure 6).

\section{Discussion}

The present study demonstrates that MSCT-based three-dimensional annulus reconstruction using the dedicated 3 mensio software allows for a highly reproducible assessment of the annulus dimensions, including perimeter, area and diameters. Differences between area and perimeter-derived virtual diameters were only small and both parameters had an excellent correlation. Compared with standard two-dimensional imaging modalities, area and

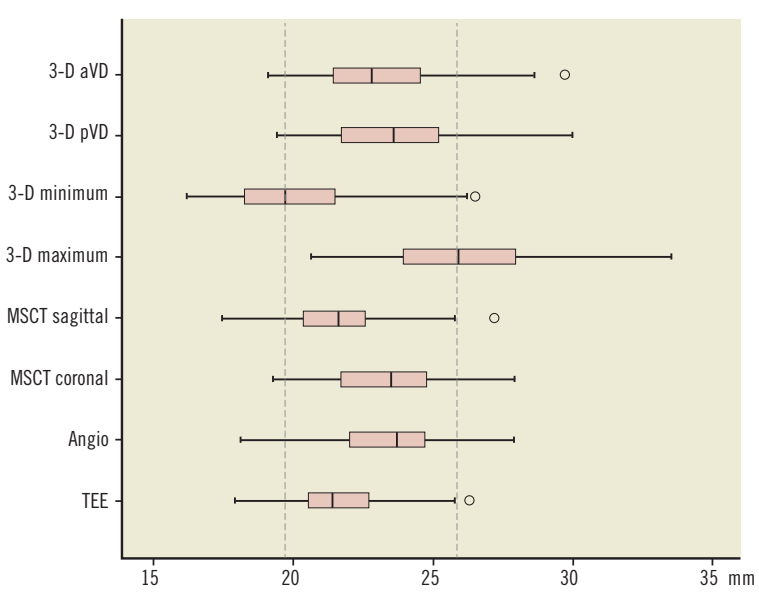

Figure 5. Annulus diameter size according to standard and 3mensio imaging techniques. 3D pVD: perimeter-derived virtual diameter; 3D aVD: area-derived virtual diameter; MSCT: multislice computed tomography; TEE: transoesophageal echocardiography

perimeter-derived virtual diameters were consistently larger than TEE and sagittal MSCT measurements and were on average in the range of angiography and coronal MSCT plane measurements. Nevertheless, looking at every single patient, there were significant inter-modality differences in a substantial number of patients.

Reasons for these discrepancies lie in the anatomic complexity of the aortic root geometry as well as the different capabilities of the various imaging techniques to describe this structure and its components. In general, definition and identification of the aortic annulus, which is a virtual ring defined by the nadirs of the three aortic valve cusps ${ }^{2}$, require an imaging technique which allows for a threedimensional reconstruction for physical reasons. MSCT, threedimensional TEE and rotational angiography offer this option with varying accuracy given their different spatial and temporary resolution as well as their varying sensitivity to artefacts (i.e., shadowing by calcifications). In contrast, conventional echocardiography and angiography cannot define the annulus, which results in a certain degree of innate imprecision. Moreover, the annulus is primarily oval in shape $\mathrm{e}^{2,6,10}$ and two-dimensional imaging techniques providing a single diameter only are not able to describe this shape, as the calculated diameter can amount to any value between the true minimal and maximal diameter. This explains the significant discrepancies observed already when making comparisons between different two-dimensional imaging techniques for annulus sizing ${ }^{13,14}$ as well as comparing conventional techniques with virtual diameters as shown in our study. Given the fact that area and perimeter-derived diameters (aVD and pVD) take into account the geometry of the annulus within the three-dimensional space, these parameters are likely to be superior to diameters obtained from two-dimensional imaging, and device selection based on these new parameters is likely to translate into a better device-to-annulus relationship and a clinical benefit with reduction of paravalvular leaks, device embolisations and annulus ruptures. Willson et al and Jilaihawi et al 
MSCT sagittal vs. perimeter-derived virtual annulus
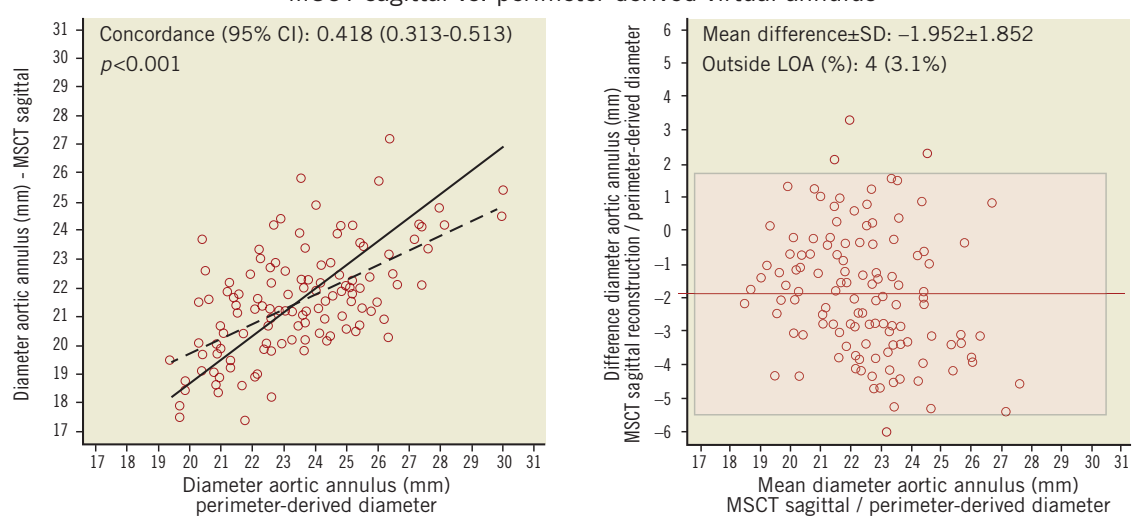

Transoesophageal echocardiography vs. perimeter-derived virtual annulus
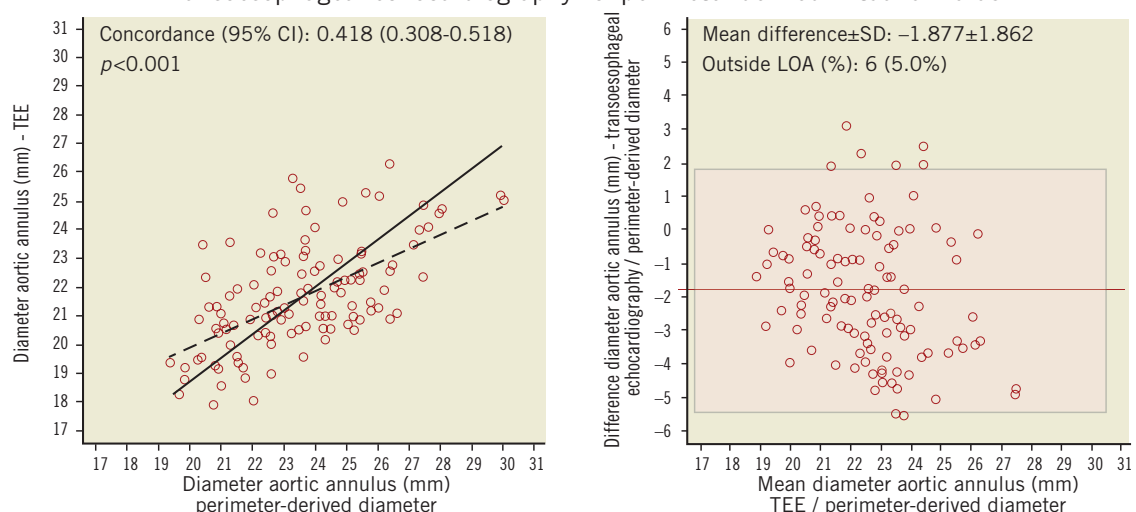

MSCT coronal vs. perimeter-derived virtual annulus
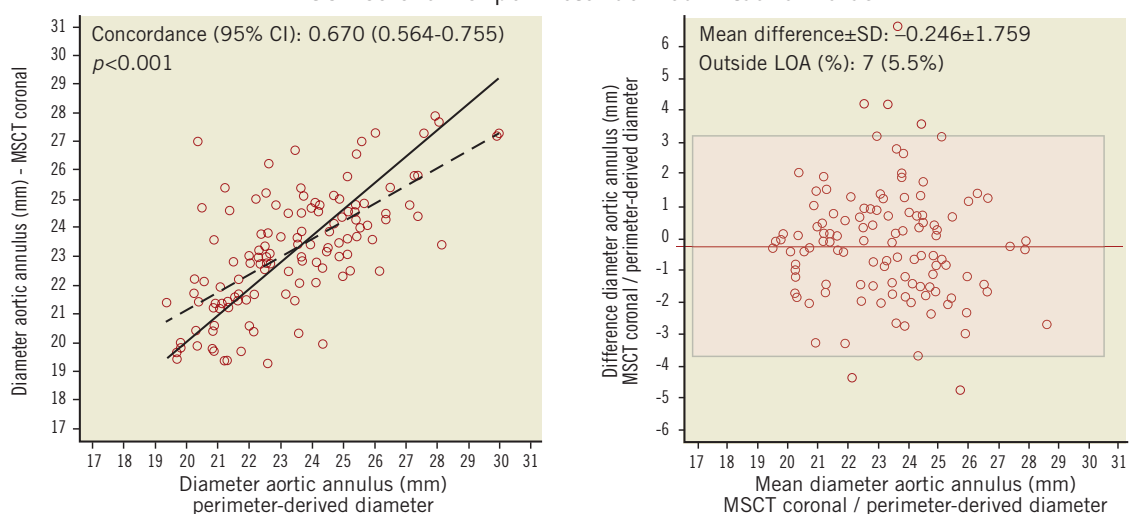

Angiography vs. perimeter-derived virtual annulus
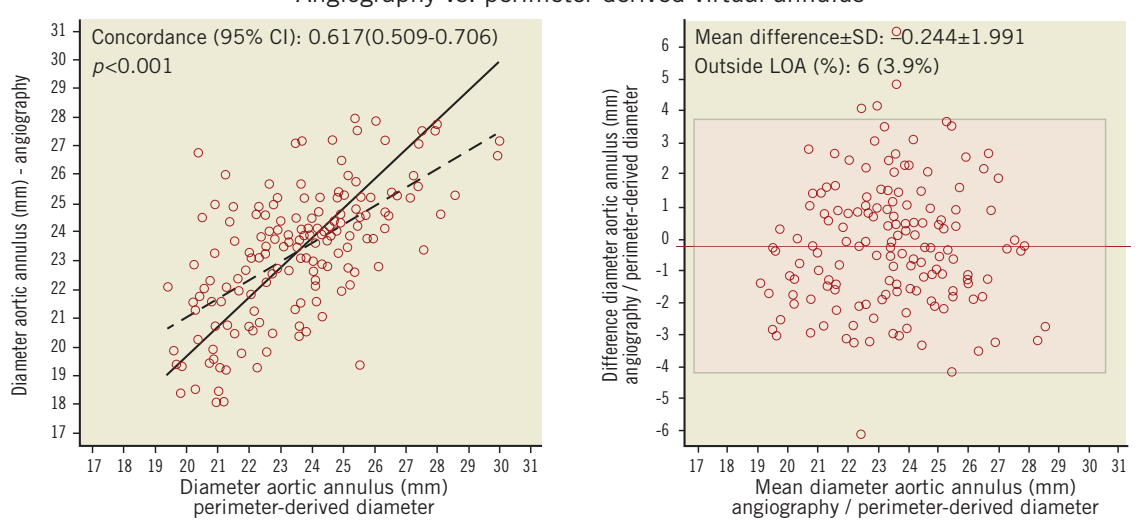

Figure 6. Inter-modality differences between 3mensio and standard aortic annulus imaging assessments. Depicted are correlation figures and Bland-Altman analysis for the comparison of perimeter-derived virtual aortic diameter compared to transoesophageal echocardiography (TEE), angiography and multislice computed tomography scan (coronal and sagittal reconstruction). 
recently described the predictive value of three-dimensional annular sizing on post-procedural aortic regurgitation ${ }^{18,19}$, but the evidence is still sparse and further studies are needed.

In addition, it still remains unclear which of the new parameters "area", "perimeter", and "virtual diameters" derived from area or perimeter calculations is the most appropriate on which to base device size recommendations. In fact, all approaches are currently being used in clinical practice ${ }^{9,18,20}$. Since device implantation affects annulus shape, transforming the initially oval structure into a more circular shape, the perimeter as the constant link is less affected by this transformation than the area size. This effect is more pronounced the more oval the initial structure. Consequently, area and perimeterderived virtual diameters are different in reality, with the area-derived diameter always being smaller than the perimeter-derived diameter unless the initial shape is a perfect circle. Nevertheless, these differences are usually very small as mentioned above and shown in this study, and, for the vast majority of patients, it is probably irrelevant whether the assessment is area or perimeter-based. However, outcome-driven studies comparing both assessment approaches are awaited to provide more evidence on this particular topic.

\section{Conclusion}

In conclusion, MSCT-based three-dimensional reconstruction using the dedicated 3 mensio software allows for a precise and reproducible assessment of aortic annulus dimensions in patients evaluated for TAVR. Unlike standard imaging techniques, this approach considers all aspects of the three-dimensional characteristics of this structure and may become the gold standard for device size selection in TAVR candidates.

\section{Limitations}

The following limitations need to be acknowledged when interpreting the results of this study. First, it is a moderately sized singlecentre study with some retrospectively enrolled patients and therefore the findings need to be confirmed in a sizeable prospective multicentre study. Second, this study did not include threedimensional echocardiography imaging which might be an alternative tool to MSCT three-dimensional reconstructions, also allowing for calculations of perimeter, area and virtual diameters. Third, the MSCT analyses were based on diastolic images. There is currently controversial evidence on the impact of the heart cycle on the annular geometry, and several studies are ongoing addressing this topic. Finally, this imaging study included patients who underwent TAVR and did not enrol an unselected population.

\section{Conflict of interest statement}

L. Buellesfeld is a consultant and proctor for Medtronic and Edwards Lifesciences. P. Wenaweser is a proctor for and receives honoraria from Medtronic and Edwards Lifesciences. S. Windecker has received research grants from Edwards Lifesciences, Medtronic, Boston Scientific and St. Jude Medical and speaker fees from Medtronic, Boston Scientific and St. Jude Medical. The other authors have no conflicts of interest to declare in relation to this study.

\section{References}

1. Holmes DR Jr, Mack MJ, Kaul S, Agnihotri A, Alexander KP, Bailey SR, Calhoon JH, Carabello BA, Desai MY, Edwards FH, Francis GS, Gardner TJ, Kappetein AP, Linderbaum JA, Mukherjee C, Mukherjee D, Otto CM, Ruiz CE, Sacco RL, Smith D, Thomas JD. 2012 ACCF/AATS/SCAI/STS expert consensus document on transcatheter aortic valve replacement. J Am Coll Cardiol. 2012;59:1200-54

2. Piazza N, de Jaegere P, Schultz C, Becker AE, Serruys PW, Anderson RH. Anatomy of the aortic valvar complex and its implications for transcatheter implantation of the aortic valve. Circ Cardiovasc Interv. 2008;1:74-81.

3. Buellesfeld L, Stortecky S, Kalesan B, Gloekler S, Khattab AA, Nietlispach F, Delfine V, Huber C, Eberle B, Meier B, Wenaweser P, Windecker S. Aortic root dimensions among patients with severe aortic stenosis undergoing transcatheter aortic valve replacement. JACC Cardiovasc Interv. 2013;6:72-83.

4. Détaint D, Lepage L, Himbert D, Brochet E, MessikaZeitoun D, Iung B, Vahanian A. Determinants of significant paravalvular regurgitation after transcatheter aortic valve: implantation impact of device and annulus discongruence. JACC Cardiovasc Interv. 2009;2:821-7.

5. Moss RR, Ivens E, Pasupati S, Humphries K, Thompson CR, Munt B, Sinhal A, Webb JG. Role of echocardiography in percutaneous aortic valve implantation. JACC Cardiovasc Imaging. 2008;1:15-24.

6. Tops LF, Wood DA, Delgado V, Schuijf JD, Mayo JR, Pasupati S, Lamers FP, van der Wall EE, Schalij MJ, Webb JG, Bax JJ. Noninvasive evaluation of the aortic root with multislice computed tomography implications for transcatheter aortic valve replacement. JACC Cardiovasc Imaging. 2008;1:321-30.

7. Jabbour A, Ismail TF, Moat N, Gulati A, Roussin I, Alpendurada F, Park B, Okoroafor F, Asgar A, Barker S, Davies S, Prasad SK, Rubens M, Mohiaddin RH. Multimodality imaging in transcatheter aortic valve implantation and post-procedural aortic regurgitation: comparison among cardiovascular magnetic resonance, cardiac computed tomography, and echocardiography. $J$ Am Coll Cardiol. 2011;58:2165-73.

8. Tzikas A, Schultz CJ, Piazza N, Moelker A, Van Mieghem NM, Nuis RJ, van Geuns RJ, Geleijnse ML, Serruys PW, de Jaegere PP. Assessment of the aortic annulus by multislice computed tomography, contrast aortography, and trans-thoracic echocardiography in patients referred for transcatheter aortic valve implantation. Catheter Cardiovasc Interv. 2010;77:868-75.

9. Gurvitch R, Webb JG, Yuan R, Johnson M, Hague C, Willson AB, Toggweiler S, Wood DA, Ye J, Moss R, Thompson CR, Achenbach S, Min JK, Labounty TM, Cury R, Leipsic J. Aortic annulus diameter determination by multidetector computed tomography: reproducibility, applicability, and implications for transcatheter aortic valve implantation. JACC Cardiovasc Interv. 2011;4:1235-45.

10. Schultz CJ, Moelker A, Piazza N, Tzikas A, Otten A, Nuis RJ, Neefjes LA, van Geuns RJ, de Feyter P, Krestin G, Serruys PW, 
de Jaegere PP. Three dimensional evaluation of the aortic annulus using multislice computer tomography: are manufacturer's guidelines for sizing for percutaneous aortic valve replacement helpful? Eur Heart J. 2010;31:849-56.

11. Hamdan A, Guetta V, Konen E, Goitein O, Segev A, Raanani E, Spiegelstein D, Hay I, Di Segni E, Eldar M, Schwammenthal E. Deformation dynamics and mechanical properties of the aortic annulus by 4-dimensional computed tomography: insights into the functional anatomy of the aortic valve complex and implications for transcatheter aortic valve therapy. $\mathrm{J} \mathrm{Am}$ Coll Cardiol. 2012;59:119-27.

12. Bertaso AG, Wong DT, Liew GY, Cunnington MS, Richardson JD, Thomson VS, Lorraine B, Kourlis G, Leech D, Worthley MI, Worthley SG. Aortic annulus dimension assessment by computed tomography for transcatheter aortic valve implantation: differences between systole and diastole. Int $J$ Cardiovasc Imaging. 2012;28:2091-8.

13. Messika-Zeitoun D, Serfaty JM, Brochet E, Ducrocq G, Lepage L, Detaint D, Hyafil F, Himbert D, Pasi N, Laissy JP, Iung B, Vahanian A. Multimodal assessment of the aortic annulus diameter: implications for transcatheter aortic valve implantation. J Am Coll Cardiol. 2010;55:186-94.

14. Kempfert J, Van Linden A, Lehmkuhl L, Rastan AJ, Holzhey D, Blumenstein J, Mohr FW, Walther T. Aortic annulus sizing: echocardiographic versus computed tomography derived measurements in comparison with direct surgical sizing. Eur $J$ Cardiothorac Surg. 2012;42:627-33.
15. de Vaan J, Verstraeten L, de Jaegere P, Schultz C. The 3mensio Valves $^{\mathrm{TM}}$ multimodality workstation. EuroIntervention. 2012;7:1464-9.

16. Delgado V, Ng AC, Schuijf JD, van der Kley F, Shanks M, Tops LF, van de Veire NR, de Roos A, Kroft LJ, Schalij MJ, Bax JJ. Automated assessment of the aortic root dimensions with multidetector row computed tomography. Ann Thorac Surg. 2011;91:716-23.

17. Lin LI. A concordance correlation coefficient to evaluate reproducibility. Biometrics. 1989;45:255-68.

18. Willson AB, Webb JG, Labounty TM, Achenbach S, Moss R, Wheeler M, Thompson C, Min JK, Gurvitch R, Norgaard BL, Hague CJ, Toggweiler S, Binder R, Freeman M, Poulter R, Poulsen S, Wood DA, Leipsic J. 3-dimensional aortic annular assessment by multidetector computed tomography predicts moderate or severe paravalvular regurgitation after transcatheter aortic valve replacement: a multicenter retrospective analysis. J Am Coll Cardiol. 2012;59:1287-94.

19. Jilaihawi H, Kashif M, Fontana G, Furugen A, Shiota T, Friede G, Makhija R, Doctor N, Leon MB, Makkar RR. Crosssectional computed tomographic assessment improves accuracy of aortic annular sizing for transcatheter aortic valve replacement and reduces the incidence of paravalvular aortic regurgitation. $J \mathrm{Am}$ Coll Cardiol. 2012;59:1275-86.

20. Koos R, Altiok E, Mahnken AH, Neizel M, Dohmen G, Marx N, Kühl H, Hoffmann R. Evaluation of aortic root for definition of prosthesis size by magnetic resonance imaging and cardiac computed tomography: implications for transcatheter aortic valve implantation. Int J Cardiol. 2012;158:353-8. 